\title{
Teaching Methods and Educational Atmosphere in Isfahan English Language Institutes: Do Teachers and Learning Facilities Make a Difference?
}

\author{
Mohammad Javad Baghazadeh Naini \\ Department of English, Shahreza Branch, Islamic Azad University, Shahreza, Iran \\ Email: javad.baghazadeh@gmail.com \\ Hossein Vahid Dastjerdi \\ Department of English, Shahreza Branch, Islamic Azad University, Shahreza, Iran \\ Corresponding Author Email: h_vahid@yahoo.com
}

\section{Doi:10.5901/mjss.2014.v5n23p1198}

\begin{abstract}
The present situation of EFL teaching in Today's Iran institutes has led many people toward private English Language Institutes. In the present study, the researchers have tried to investigate ten of the top institutes of Isfahan (a metropolitan city located in central Iran), in order to analyze their main teaching methods and find about their possible key elements of success. To this purpose, the selection of the top institutes was done according to a set of criteria based on which amongst 43 active boy institutes of the city, 10 were chosen. Then, in a narrower selection, 190 students and 23 teachers from 2-3 of the high intermediate classes of each selected institute, were chosen to reply to the researcher-made questionnaires. The required data were derived from these questionnaires and an observation check list, and then they were analyzed on a single-question basis. The analysis showed that factors like proximity to institute, physical atmosphere of the classes, teachers' freedom of choice in supplementary methods, fame of the institute, the type of the activities infiltrated in textbooks, financial factors, and much more, were all vital parameters in establishing and running successful EFL institutes. The findings of this study can be exploited to enhance the existing institutes' quality level by considering such educational factors in language teaching institutes. They can also help new founders decide where and how to establish a quality language institute in similar contexts the world over.
\end{abstract}

Keywords: English language institutes, educational atmosphere, teaching methods, educational factors, quality language institutes

\section{Introduction}

Education in Iran has had a long history since ancient Persia (650 BC) when the religious ideas of Zoroastrianism were taught, to the recent modern time. Throughout this long period, attention to the necessity of learning a foreign language (which was mostly Arabic in the Iranian history) was felt from the 11th century when trading caravans were sent to Arabic speaking parts of the Middle-East (Vakilian, 1999). Throughout the centuries this need to teach and learn foreign languages continued to grow and by the emerging of "globalization" this industry was also at the center of attention; however, it did not receive the adequate consideration it needed in the Iranian public education system. There are studies seeking reasons for this loss, which are beyond the scope of the present paper.

Today, at junior high institutes of Iran, learners spend four hours a week learning English and during the three years at high institute they have a six unit credit English course. In addition, in the fourth year of high institute, they are required to pass a four unit credit English course (Farhady, Hezaveh and Hedayati (2010).

The textbooks in high institute focus on grammar, vocabulary and reading comprehension and the methodology for teaching them is basically grammar-translation and audio-lingualism, but reading "skills" are not usually taught in the three years of language learning in high institutes. In the fourth-grade English textbooks there seems to be more topics and contents related to science and technology and the teaching of reading skills with a deeper comprehension of passages is intended. Razmjoo (2007) compared textbooks taught in high institutes and private institutes in terms of the extent they fulfill the communicative principles in the Iranian context and concluded that institute textbooks fail to reflect the CLT principles.

Riazi and Mosalanejad (2010) also investigated the types of learning objectives in the high institute and fourth grade English textbooks using Bloom's (1956) Taxonomy and found lower-order cognitive skills in all the grades of high institute textbooks. It is mentioned there that the criteria of Williams D. (1983) has not been considered in our textbooks 
either. Apart from that, the criteria mentioned by Richards (2001) in his book on curriculum development have also been neglected in our public EFL context. According to Jahangard (2007), the nationwide exams which are administered in the third year of high institute and English part of the University Entrance Examination (UEE) determine the norm for our foreign language teaching and foreign language test classroom construction.

In the present study, the researchers have tried to cast a look at private English institutes of Isfahan (a metropolitan city located in central Iran) with the main focus on the way they are giving services to EFL learners. Throughout this study, attempts have been made to investigate the different positive aspects of a Megacity's popular and successful institutes, in order to collect them in one unified manual and render it to the prospective institute founders and investors. The result of this research and the other similar researches in this field will definitely help the prospective founders to establish high quality language institutes in Iran and other similar contexts where students will really learn better.

The pivotal points of this study thus include: 1) the main teaching method(s) being used in the institutes, 2) the textbook(s) being taught, 3) the geographical place (in terms of the social levels of the people, etc.), 3) the fees and students payment terms and conditions, and 4) the size and average surface of the classrooms. These factors have been well spotted and contrived in the researcher-made questionnaires and observation check list exploited in this study.

\subsection{Statement of the problem}

As it is seen in the present educational society of Iran, considering the malfunction of our public educational system in teaching EFL students and training teachers accordingly, most of the people especially in our major cities are heading towards private language institutes for learning English as well as other mostly European languages. This trend has had significant increase in recent years and thus it is not much difficult to find small and big institutes in nearly every corner of our big cities, which render educational services in the field of foreign language(s). This abundance is appreciable when it comes to providing people and learners with easy access to such places for learning languages. But, are all these institutes providing their due educational services on the basis of the latest scientific research findings and expertise gained and worked on in Applied Linguistics? In other words, have these institutes based their services on educational and scientific methods and scales? Is it not necessary to determine, verify, modify and even revise the teaching methods, educational insights, testing approaches, Teacher Training Courses, the ways an institute tests and employs teachers, and the ways new students are placed at different levels of study defined in an institute? How much importance should necessarily be allocated to parameters like class size, lighting and air conditioning, the standard number of students present in a class, etc. in such institutes? And what is the relationship between the popularity of an institute and the required parameters of educational quality? Finally, is it possible to verify the positive points of successful institutes and come up to a conclusion on a "unified quality manual" for establishing a proper language institute, which can be appropriate both scientifically and financially?

\subsection{Research Questions}

Based on what was stated above, the following research questions were initially set forth for this study:

- What teaching methods are dominantly used in Isfahan EFL institutes?

- To what extent are the used methods virtually followed by teachers in different institutes in terms of educational quality factors?

- Is it possible to combine the positive aspects of the selected top institutes and accordingly form a unified manual for establishing an ideal EFL institute in Isfahan and in similar contexts elsewhere?

\section{Method}

\subsection{Instruments}

The needed data for this research was collected mainly through the following three instruments:

1. The most important data collection tool was the researcher-made questionnaires filled by the students and teachers of the institutes. These questionnaires were designed by the researchers in order to exactly meet the requirements of the data needed.

2. The second major tool was an observation check list prepared for determining the physical and educational factors of the institutes. The items of the check list were also mostly designed and validated by the 
researchers.

3. Finally, there were the interview questions-- a mélange of typical questions found online and the questions designed by the researchers to meet the study's specific purposes. (For the details of all the employed instruments, see the Appendix.)

\subsection{Participants}

To conduct the research, it was firstly needed to define a criterion on "being/not being successful" (i.e. "popularity") for a given institute:

1- The number/frequency of complaints the learners or their families have made to the ministry of education (or any other authorizing body) against that institute, as well as the number of appreciation certificates the institute has obtained from the authorizing body. It is noteworthy, however, that this factor was subject to restrictive objections for disclosure by the Ministry of Education, and thus was eliminated from the criteria list.

2- The frequency of high intermediate and advanced terms being held in a special institute.

3- The total number of the learners the institute had in one specific year.

The data elicited from such institutes was combined with the results obtained from the frequency of the high intermediate and advanced terms held in the institute (factor number 2 above), and finally as seen in the coming tables, the final 10 institutes were chosen considering the correlation between the above two elements. In practice, it was revealed that there might be some problems (cultural, etc.) with observing the girls EFL institutes, so they were excluded from the study. So, Out of $254 \mathrm{EFL}$ institutes in Isfahan, amongst which 112 were currently active, 43 male institutes were selected as the accessible population of the study.

In the following tables you will see the labels of the 43 institutes, and the rate of the above-mentioned 2 factors. Thus, considering these data, the final institutes investigated were finally determined as follows.

As the comparison between the tables shows hereunder, the correlation that the researchers expected to exist Did exist in the two parameters; meaning that logically enough and with no exception, the institutes with bigger number of students enrolled, were more likely to have their upper intermediate terms held. So, the finally selected institutes were the following:

Nos. 1,2,3,12,15,16,17,41, 42.

Comparison in terms of the first factor:

Table 1. Total number of students enrolled in the year 1392 (institutes 1-14)

\begin{tabular}{|c|c|c|c|c|c|c|c|c|c|c|c|c|c|}
\hline$\# 1$ & $\# 2$ & $\# 3$ & $\# 4$ & $\# 5$ & $\# 6$ & $\# 7$ & $\# 8$ & $\# 9$ & $\# 10$ & $\# 11$ & $\# 12$ & $\# 13$ & $\# 14$ \\
\hline 2350 & 2600 & 2000 & 1380 & 1090 & 1878 & 1700 & 1500 & 870 & 690 & 1750 & 2405 & 1500 & 1200 \\
\hline
\end{tabular}

Table 2. Total number of students enrolled in the year 1392 (institutes 15-28)

\begin{tabular}{|c|c|c|c|c|c|c|c|c|c|c|c|c|c|}
\hline$\# 15$ & $\# 16$ & $\# 17$ & $\# 18$ & $\# 19$ & $\# 20$ & $\# 21$ & $\# 22$ & $\# 23$ & $\# 24$ & $\# 25$ & $\# 26$ & $\# 27$ & $\# 28$ \\
\hline 2610 & 2420 & 2500 & 1800 & 1620 & 1500 & 1700 & 1140 & 780 & 752 & 1370 & 610 & 504 & 900 \\
\hline
\end{tabular}

Table 3. Total number of students enrolled in the year 1392 (institutes 29-43)

\begin{tabular}{|c|c|c|c|c|c|c|c|c|c|c|c|c|c|c|}
\hline$\# 29$ & $\# 30$ & $\# 31$ & $\# 32$ & $\# 33$ & $\# 34$ & $\# 35$ & $\# 36$ & $\# 37$ & $\# 38$ & $\# 39$ & $\# 40$ & $\# 41$ & $\# 42$ & $\# 43$ \\
\hline 2300 & 600 & 380 & 700 & 1835 & 1098 & 890 & 883 & 640 & 410 & 750 & 800 & 2100 & 1900 & 370 \\
\hline
\end{tabular}

Comparison in terms of the second factor:

Table 4. Number of the three final advanced terms held in 92 (Institutes 1-14)

\begin{tabular}{|c|c|c|c|c|c|c|c|c|c|c|c|c|c|}
\hline$\# 1$ & $\# 2$ & $\# 3$ & $\# 4$ & $\# 5$ & $\# 6$ & $\# 7$ & $\# 8$ & $\# 9$ & $\# 10$ & $\# 11$ & $\# 12$ & $\# 13$ & $\# 14$ \\
\hline 23 & 26 & 20 & 13 & 11 & 18 & 17 & 15 & 8 & 7 & 17 & 24 & 15 & 12 \\
\hline
\end{tabular}


Table 5. Number of the three final advanced terms held in 92 (Institutes 15-28)

\begin{tabular}{|c|c|c|c|c|c|c|c|c|c|c|c|c|c|}
\hline$\# 15$ & $\# 16$ & $\# 17$ & $\# 18$ & $\# 19$ & $\# 20$ & $\# 21$ & $\# 22$ & $\# 23$ & $\# 24$ & $\# 25$ & $\# 26$ & $\# 27$ & $\# 28$ \\
\hline 26 & 24 & 25 & 18 & 16 & 15 & 17 & 11 & 7 & 7 & 13 & 6 & 5 & 9 \\
\hline
\end{tabular}

Table 6. Number of the three final advanced terms held in 92 (Institutes 29-43)

\begin{tabular}{|c|c|c|c|c|c|c|c|c|c|c|c|c|c|c|}
\hline$\# 29$ & $\# 30$ & $\# 31$ & $\# 32$ & $\# 33$ & $\# 34$ & $\# 35$ & $\# 36$ & $\# 37$ & $\# 38$ & $\# 39$ & $\# 40$ & $\# 41$ & $\# 42$ & $\# 43$ \\
\hline 23 & 6 & 4 & 7 & 17 & 11 & 8 & 8 & 7 & 3 & 8 & 9 & 21 & 19 & 4 \\
\hline
\end{tabular}

So, the selected institutes are: 1,2,3,12,15,16,17,29,41,42.

So far, we have talked about the procedure of choosing the institutes we investigated. The other factor vital in the final selection of the participants, was the proficiency level of the students in these selected institutes. The institutes of course included different and diverse ranges of students from beginner to intermediate and advanced levels. For the case of the present study, the researchers decided to work on the advanced level students. Although this would make some problems with the validity of the results, they cosidered the following logical reasons for such a decision: Firstly, because of the time limitations, and secondly because high level students are "fruits" of any educational system, i.e. they are usually good indicators of the system in which they have been trained and taught language.

All in all, among different levels of proficiency in the selected institutes, all the advanced adult language learners (190 students) and their teachers (23 teachers) were chosen for the study. In order to complete the results of the study and come to a truly acceptable conclusion and viewpoint on the subject matter that the study sought to clarify, the researchers also designed face to face interviews with the selected institute administrators as well as with the educational directors. To avoid staff time consumption, the questions of the interview were not so many, and were validated by Islamic Azad University professors.

\subsection{Procedures}

In each institute, depending on the classes chosen, the number of respondents was different, but all in all there were 190 students who responded to the questionnaires. In each institute, the teachers of the chosen classes were also given their own questionnaires and the 2-3 official staffs were interviewed as well (in cases of the institutes \#16, \#29 and \#41 only one person was available to interview).

\section{Results}

The data obtained from the questionnaires was analyzed on a single-question-basis in order to be able to render the most analytical view on each question in the whole population of respondents. Unlike the questionnaires' analysis which was based on all the respondents' replies, the results of the interviews and institutes' educational atmosphere check lists were obtained from all the institutes, in a distinctive way from the results derived from the questionnaires. In the first questionnaire for the students, there were 12 questions and in the second, there are 20 questions.

\section{Discussion and Concluding Remarks}

This study was done on the top 10 English Language Institutes of Isfahan, Iran. The research was basically conducted for the purpose of finding the methodologies and other learning-effective factors of successful institutes in a Metropolitan area. The researchers sought not only the analysis of the institutes, but also the possibility of collecting their most powerful aspects and possible key elements of success in order to prepare a "quality manual" for establishing a quality institute in any Metropolitan city throughout the world.

The question-based analysis of the questionnaires revealed some very important points to consider as rules of success for the analyzed institutes. Meanwhile, the positive aspects of the institutes were also discovered to be "mostly combinable" for establishing a new institute with regard to the standards found. However, it is mentionable that these points are practicable once their specific infrastructures are provided and the necessary contexts and conditions are met. The following are some of the points derived from this study which can be considered as a scientifically examined basis or manual for establishing a quality language institute in a Metropolitan City over the globe. 
- The proximity to or easy accessibility of the institute is an advantage. But, simultaneously this study showed that the socio-geographical place of the institute is of not much importance to the students. This is a great point to be considered by the new founders to conduct researches on the places where the students come from and establish their institutes in areas where their students do not have easy access to other language institutes.

- The physical aspects of the classroom (e.g lighting, ventilation and seats arrangement)-taken from the checklists analysis- have been reported not much satisfactory, but truly remarkable to the students. This shows the importance of this issue for the new founders who want to attain more customer satisfaction in this respect.

- The relative and controlled freedom of the teachers in an EFL class, especially while choosing supplementary methods helps them a lot in providing better and more efficient teaching.

- Speaking the students' first language (in the case of the present study, Persian) should be strictly forbidden in the class except for very rare cases of very few words or short phrases.

- The fees should be normal. The students do not show a very positive attitude towards the class fees. Offering alternative payment methods and conditions (like installments, etc.) also helps the institute gain more popularity, especially in poorer areas.

- The way the teachers act and behave in the classroom is strongly related to the degree of popularity a institute has! In addition to this point, the way the teacher teaches communicatively and the amount of listening and speaking activities the teacher has in the class are also very important.

- Choosing a good textbook which the students also enjoy can be a very determinant element of success.

- The most important characteristics a textbook should have are authenticity, focusing on the skills and needs of the students, and focusing on communicative teaching and interactive tasks. Apart from that, the language of the textbook should be close to the current level of the students'. It was also revealed that the balance of the four skills is also prominent in a good textbook.

- The salary of the teachers should be paid in a satisfying way and amount. It is very important to note that a powerful educational system cannot continue firmly and for a long time without financially satisfied teachers (or at least a fixed group of them). In other words, a successful language institute should at least keep a set of fixed teachers happy!

- Since the name and fame of the institutes are important to the teachers, good teachers are very likely to be found in famous institutes.

- Letting teachers perform their own task-based activities -besides the main textbook activities- helps them teach much more effectively. The teachers should be respected, and in case they have any ideas, suggestions or complaints, there should be meetings and gatherings every now and then, so that they are "heard" easily and in a friendly manner.

- If an institute seeks success, the whole system should try its best to create and maintain an atmosphere where "committed" teachers become "loyal". This will surely end up in "committed" and "loyal" students too.

To all the above points we should also add the very important note previously mentioned by Zhang, L.F (2009), about the prominence of the teachers' ability to cope with different students of different learning styles. This is not something every institute can provide its students with. This study showed that even in the top institutes under scrutiny, there were very few interviewed teachers showing positive feedback regarding this issue.

\section{References}

A. Razmjoo, "High Institutes or Private Institutes Textbooks? Which Fulfill Communicative Language Teaching Principles in the Iranian Context? " Asian EFL, Asian EFL Journal Press, British Virgins Islands, 2007, pp. 126-140.

A. Riazi, and N. Mosalanejad, "Evaluation of Learning Objectives in Iranian High-Institute and Pre-University English Textbooks Using Bloom's Taxonomy." TESL-EJ, University of California, Berkeley, 2010;

A. Jahangard, "Evaluation of EFL Materials Taught at Iranian Public High Institutes." Asian EFL, Asian EFL Journal Press, British Virgins Islands, 2007a, pp. 130-150.

Bloom, B. S, Taxonomy of educational objectives handbook: Cognitive domain. McKay, New York, 1956

H. Farhady, F. S. Hezaveh, and H. Hedayati, "Reflections on Foreign Language Education in Iran", TESL-EJ, University of California, Berkeley, 2010;

Mahmoudian, "Tarikhe Amuzesh va Parvareshe Iran-e Bastan" [History of Education in Ancient Persia]. Roshd-e Amuzesh-e Rahnamei, Amuzesh va Parvaresh, Tehran, 2010; http://www.roshdmag.ir/ Roshdmag_content/media/article/1954.pdf

Richard Nelson Frye, Cambridge history of Iran Vol.4, 1983, Cambridge University Press, 1983. 
Richards, J. C, Curriculum Development in Language Teaching, Cambridge University Press, Cambridge, 2001.

Vakilian, M, Tarikhe Amuzesh va Parvaresh-e Iran va Islam. [History of Eduction in Iran and Islam]. Payam-e Nour University, Tehran, 1999.

Williams, D. (1983). Developing criteria for textbook evaluation. ELT Journal, 37(3), 251-261. http://dx.doi.org/10.1093/elt/37.3.251

Zhang, L. F. (2009). From conceptions of effective teachers to styles of teaching: Implications for higher education. Learning and Individual Differences, 19, 113-118.

\section{Appendix}

\section{Dear Student,}

\section{A. Students' Questionnaire}

Thanking you so much for the time you are allocating to this research questionnaire, please answer these questions carefully circling the appropriate number.

*** Please note that your replies will be kept 100\% confidential. They will be viewed by NO ONE except the researcher, nor will your name or even your school's name be asked or shown anywhere. So feel free to reply. Thanks again. (The researcher) Agree / disagree questions:

\section{1-Highly agree 2- Agree 3- Average 4- Disagree 5- Highly disagree}

1- It is easy for me to get to and return from this school. I live or work near the school so I have no problem for coming and going. (RQ3)

12345

2- I like the social-geographical place of the school in the city, no matter how far it is from my house. (i.e. It is important for me that the school is located in a "special" or "well-known" part of the city.) (RQ3)

\section{5}

3- I like the physical atmosphere of the school (lighting, class sizes, ventilation, etc.) (RQ3)

$$
12345
$$

4- The teachers don't follow the instructions of the book and the official staff. They teach in the way they prefer. (RQ2)

$$
12345
$$

5- In higher terms, the teachers never speak Persian in the class. Their methods are truly communicative. (RQ1)

$$
12345
$$

6- $\quad$ The tuition fees of this school are reasonable for me (or my parents). I can pay easily (cash or in installments) with no worry about it. (RQ3)

$$
123 \quad 45
$$

7- The way the teachers teach and manage the class, makes me feel happy for studying in this school. RQ2

$$
\begin{array}{lllll}
1 & 2 & 3 & 4 & 5
\end{array}
$$

8- $\quad$ The teachers of this school generally behave and teach well (i.e. Most of them are friendly and kind, and respect the students, and teach us to communicate in English). (RQ1)

\section{$\begin{array}{lllll}1 & 2 & 3 & 4 & 5\end{array}$}

9- I like the book being taught here. I enjoy it. (RQ3)

$$
\begin{array}{lllll}
1 & 2 & 3 & 4 & 5
\end{array}
$$

10- If there was another English language school nearer to my house, I would choose that, no matter if it was newly founded or less famous than the one I attend now. (RQ3)
$\begin{array}{lllll}1 & 2 & 3 & 4 & 5\end{array}$

11- I chose this school because the method is conversational based, rather than grammar based. (RQ1)

12345

12- I admire the degree to which the school, the book and the teachers emphasize on speaking and listening activities in the class. (RQ1)

$\begin{array}{lllll}1 & 2 & 3 & 4 & 5\end{array}$ 


\section{B. Teachers' Questionnaire}

Dear Teacher,

Thanking you so much for the time you are allocating to this research questionnaire, you are kindly asked to answer these questions carefully. Please circle the appropriate number.

*** Please note that this questionnaire has been designed for scientific purposes only, and your replies will be kept $100 \%$ confidential. They will be viewed by NO ONE except the researcher, nor will your name or even your school's name be asked or shown anywhere. So feel free to reply. Thanks again. (The researcher)

Textbook questions: (from DAVID R. A. LITZ)

\section{1-Highly agree 2- Agree 3- Average 4- Disagree 5- Highly disagree}

1- The textbook provides a balance of activities and the activities encourage sufficient communicative and meaningful practice. (RQ1)

$$
\begin{array}{lllll}
1 & 2 & 3 & 4 & 5
\end{array}
$$

2- The materials include and focus on the skills that the students need to practice. (RQ1)

$$
\begin{array}{lllll}
1 & 2 & 3 & 4 & 5
\end{array}
$$

3- The language used in the textbook is authentic. (RQ1)

$$
\begin{array}{lllll}
1 & 2 & 3 & 4 & 5
\end{array}
$$

4- The language used is at the right level for the students' current English ability. (RQ2)

$$
\begin{array}{lllll}
1 & 2 & 3 & 4 & 5
\end{array}
$$

5- The progression of grammar points and vocabulary items is appropriate. (RQ2)

$$
\begin{array}{lllll}
1 & 2 & 3 & 4 & 5
\end{array}
$$

6- The language functions exemplify English that the students will be likely to use in the future. (RQ1)

$$
\begin{array}{lllll}
1 & 2 & 3 & 4 & 5
\end{array}
$$

7- The grammar points and vocabulary items are introduced in motivating and realistic contexts. (RQ2)

$$
\begin{array}{lllll}
1 & 2 & 3 & 4 & 5
\end{array}
$$

8- The materials provide an appropriate balance of the four language skills. (RQ1)

$$
\begin{array}{lllll}
1 & 2 & 3 & 4 & 5
\end{array}
$$

9- The language used in the textbook is authentic while materials are not culturally biased and they do not portray any negative stereotypes. (RQ2)

$$
\begin{array}{lllll}
1 & 2 & 3 & 4 & 5
\end{array}
$$

10- The subject and content of the textbook is relevant to the students' needs as English language learners. (RQ1)

$\begin{array}{lllll}1 & 2 & 3 & 4 & 5\end{array}$

\section{1-Highly agree 2- Agree 3- Average 4- Disagree 5- Highly disagree}

Teachers' questions:

11- In-line with the school's general policies and regulations, I do have the freedom to apply teaching method(s) of my choice, depending on the class level and the specific lesson. (RQ2)

$$
\begin{array}{lllll}
1 & 2 & 3 & 4 & 5
\end{array}
$$

12- The name and fame of the school(s) where I choose to teach are important for me. (RQ3)

$$
\begin{array}{lllll}
1 & 2 & 3 & 4 & 5
\end{array}
$$

13- I would choose to teach in a less famous school in case they offered better payments. (RQ3)

$$
\begin{array}{lllll}
1 & 2 & 3 & 4 & 5
\end{array}
$$

14- I find the general methodology of this school in-line with communicative language learning principles. (RQ1)

$\begin{array}{lllll}1 & 2 & 3 & 4 & 5\end{array}$ 
15- We are permitted to apply a variety of task based activities and the tasks are mostly communicative. (RQ1)

$\begin{array}{lllll}1 & 2 & 3 & 4 & 5\end{array}$

16- I appreciate the school decision of selecting the present textbook. (RQ1)

$$
\begin{array}{lllll}
1 & 2 & 3 & 4 & 5
\end{array}
$$

17- In the general policy of this school, the teachers' ideas, experiences and educational viewpoints are appreciated and welcome. (There are useful introductory seminars, get-togethers, etc. in this regard.) (RQ2)
$\begin{array}{lllll}1 & 2 & 3 & 4 & 5\end{array}$

18- Compared to other places I have taught, I find nice, special and positive points in the teaching policies and methodology of this school. (RQ2)
$\begin{array}{lllll}1 & 2 & 3 & 4 & 5\end{array}$

19- Putting the financial issues apart, I really "enjoy" the teaching methodologies here. This makes me feel sort of "loyal" to this school. (RQ2)

$\begin{array}{lllll}1 & 2 & 3 & 4 & 5\end{array}$

20- I agree with and appreciate the teaching methods and pedagogical considerations of the school policy makers. (RQ1)
$\begin{array}{lllll}1 & 2 & 3 & 4 & 5\end{array}$

\section{Physical Observation check list}

1- Does the school have a yard?

Yes No

2- How many classes are there in the school?

Less than 7 7-12 More than 12

3- How many floors are there?
$\begin{array}{lllll}1 & 2 & 3 & 4 & \text { more }\end{array}$

4- How many students are there in a typical class?

10-15 15-20 more than 20

5- Do the classes have windows?

All Nearly All Some

6- Is each class equipped by ventilation systems?

Yes, and they seem OK yes, but they seem Not enough Some classes aren't !

7- $\quad$ Any parking facilities available?

Yes No

8- Is lighting enough in every class?

Yes To some extent Not much Lighting available

\section{Interview Questions}

1- How long have you been teaching / working for this school?

2- How many classes have you been given this semester?

3- Are the teachers changing all the time? (New teachers are hired every time?)

4- How do you like the friendly atmosphere of the teachers' office?

5- Do you think it is the best school among the ones you teach / have taught in?

6- $\quad$ Are the salaries paid on a timely manner?

7- In your idea, to what extent are the teaching methods of this school effective? What are the methods' weak points in your idea?

8- What types of materials (books and others) are used in this institute?

9- What are the criteria for selecting teachers in this institute?

10- 5. How are language learners assessed in this institute? 